\title{
Development of an integrated low-carbon heating system for outdoor swimming pools for winter application
}

\author{
Yantong $\mathrm{Li}^{1}$, and Gongsheng Huang ${ }^{1, *}$ \\ ${ }^{1}$ Department of Architecture and Civil Engineering, City University of Hong Kong, Tat Chee Avenue, Kowloon, 999077, Hong Kong
}

\begin{abstract}
This paper presents an integrated low-carbon heating system for outdoor swimming pools, which aims to make outdoor swimming pools in subtropical climates available in winter season with economic feasibility. The heating system consists of solar heat collectors, air-source heat pumps, and PCM storage tanks. The solar heat collectors collect heat from solar radiation; while the air-source heat pumps collect heat from ambient air. The PCM storage tanks are used to store the heat collected by the air-source heat pumps during off-peak hours and supply heat during the open hours of outdoor swimming pools when the solar heat is insufficient. We investigated the collaboration of the two heating sources at the design stage regarding energy and economic performance using numerical simulation. Three cases with different percentage of heat contribution from these two sources were studied and compared using the indices of initial investment, operational cost, energy use and thermal comfort unmet percentage. Results were analysed to show how the percentages of the heat contribution from the two sources affect the energy and economic performance of the proposed heating system.
\end{abstract}

\section{Introduction}

Outdoor swimming is a popular sport in many subtropical regions, such as Hong Kong and the Greater Bay Area of China. In summer, due to the hot and humid weather in such a region, the water temperature of outdoor swimming pools can be easily maintained above $28^{\circ} \mathrm{C}$ without any heat input. However, in winter, although the outdoor temperature is always higher than $10^{\circ} \mathrm{C}$, many outdoor swimming pools are closed because there is a large amount of heat required to maintain the water temperature at the comfort level of $28^{\circ} \mathrm{C}$ [1-5]. Traditional heating systems, such as using gas boiler or electrical heaters, are not widely used due to their high operating cost $[6,7]$. Hence, it is necessary to develop a low-carbon heating system with low operating cost for outdoor swimming pools in subtropical regions.

Many advanced heating techniques have been developed to provide heat for outdoor swimming pools, such as solar heat collectors [8-13], heat pumps [14-17], geothermal energy [18], biomass heater [7], waste heat recovery [19, 20], PCM storage [21]. However, most of the existing studies mainly focused on a single heating source. For example, the solar collector technology cannot provide heat for the swimming pool when the solar irradiation is weak $[22,23]$, especially during the night. In this case, it is hard to achieve the preheating of the swimming pool before its open period, which results in lower water temperature at the beginning of the open period. Other heating technologies like air-source heat pump technology are therefore needed to be applied to preheat the swimming pool. In order to enhance the economic performance of the system, air-source heat pumps are suggested to be used during the off-peak period, in which the electricity price is lower than that during the on-peak period. Hence, thermal energy storage technologies like the utilization of PCM storage tank are adapted to achieve this goal [24]. From the aforementioned description, it is very necessary and meaningful to develop an open-air swimming pool heating system adapting multiple heating techniques.

This study therefore proposes an integrated lowcarbon heating system for the open-air swimming pool, which is made up of solar collector, air-source heat pumps, and PCM storage tank. The solar heat collector is applied to directly provide heat for the open-air swimming pool during the daytime. The air-source heat pumps are used to collect heat from the ambient air during the electricity offpeak time. One purpose of the collected heat is to preheat the swimming pool, and another purpose is to charge the PCM storage tank. The heat stored in the PCM storage tank will be released to heat the swimming pool during the open period. The working principle and basic control strategy of the proposed system are carried out. In addition, the main components sizing approach is proposed to determine the heating capacity of the airsource heat pumps, the volume of the PCM storage tank, and the area of the solar collector. Performance evaluation of the proposed system are conducted based on the established simulation platform. The thermal comfort unmet percentage, initial cost, operational cost and total energy use are selected as the performance indicators. The performance of the system in three typical cases are

* Corresponding author: gongsheng.huang@ cityu.edu.hk 
compared and analyzed, which assesses the proposed system in detail.

The rest of the paper is organized as follows. Section 2 describes the proposed open-air swimming pool heating system. Section 3 shows the sizing method of the main components. The design optimization approach of the system is carried out in Section 4. Section 5 presents the case studies. Concluding remarks are given in Section 6 .

\section{System description}

Fig. 1 shows the main components of the proposed lowcarbon heating system for outdoor swimming pools. The system mainly consists of solar collectors, air-source heat pumps, PCM storage tanks, and thermal-insulation cover. The solar collectors collect heat from solar radiation and supply heat directly to the swimming pool when the solar radiation is available. The air-source heat pumps collect heat from the ambient air and has two functions: one is to preheat the swimming pool before it is open in order to ensure the water temperature comfortable at the beginning of the open period; another is to charge the PCM storage tank during the off-peak period. The heat stored in the PCM storage tank is used as supplementary heat, being released to the swimming pool when the solar heat is not enough. The thermal-insulation cover is used to reduce the heat loss when the swimming pool is closed.

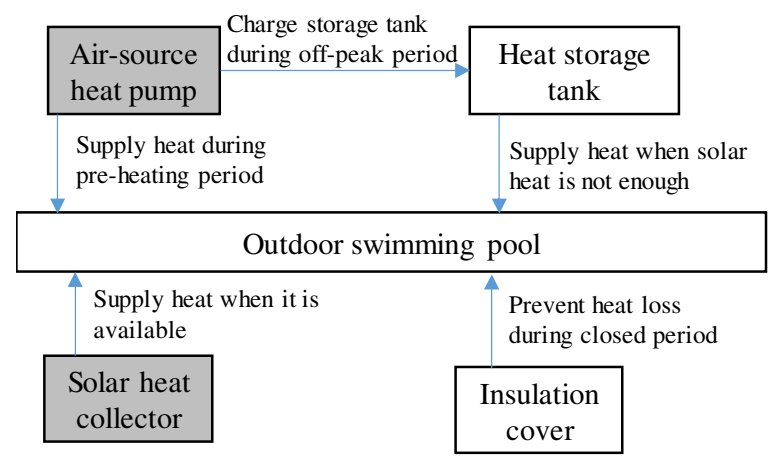

Fig. 1. The proposed low-carbon heating system for outdoor swimming pools.

In this system, heat comes from two sources: ambient air and solar radiation. Both of them suffers from stochastic changes. Therefore, how to size the capacity of the main components is an important issue, which is strongly relevant to the reliability of the system. Another important issue is to allocate the heating capacity to the air-source heat pumps and the solar heat collectors, which will affect the system annual energy use, the system annual operation cost as well as the thermal comfort of the swimming pool. Therefore, a method is proposed to size the main components and another to optimize the system design regarding energy performance, thermal comfort and annual operation cost.

\section{Main components sizing}

The basic sizing criterion is to ensure that the daily heat energy provided by the heating system can satisfy the maximum daily heat energy requirement of the swimming pool for maintaining the water temperature at comfortable level during the open period. Thus, the first step for the components sizing is to find the maximum daily heat energy requirement. To this end, a swimming pool heat loss model is needed. This model is used to estimate the heat energy loss when the swimming pool water temperature is maintained at the comfortable level under a design day. The design day should be chosen from historical daily weather data, under which the heat energy loss reaches the maximum.

As the heat energy is supplied from both the solar heat collector and the PCM storage tank, the second step is to specify the percentage contribution from both sources. Assume the maximum daily heat energy requirement is $E_{m}$ and the percentage contribution from the solar heat collector is $\gamma$, then the daily heat energy that should be contributed by the solar heat collector $E_{S c}$ is

$$
E_{s c}=\gamma E_{m}
$$

The daily heat energy that should be contributed by the PCM storage tank $E_{p c m}$ is

$$
E_{p c m}=(1-\gamma) E_{m}
$$

The third step is to use $E_{s c}$ to size the area of the solar heat collector.

$$
A_{s c}=E_{s c} /\left(T S_{\text {open }, d}\right)
$$

where $A_{s c}$ is the area of the solar heat collector, $T S_{\text {open, } d}$ is the designed total solar irradiation during the open period, which is determined by the following equation:

$$
T S_{\text {open }, d}=T S_{\text {open }}\left(\varphi=\varphi_{\text {open }}\right)
$$

where $\varphi$ is the cumulative probability of less than $T S_{\text {open }}$. The schematic of the relationship between the total solar irradiation during the open period and cumulative probability is shown in Fig. 2.

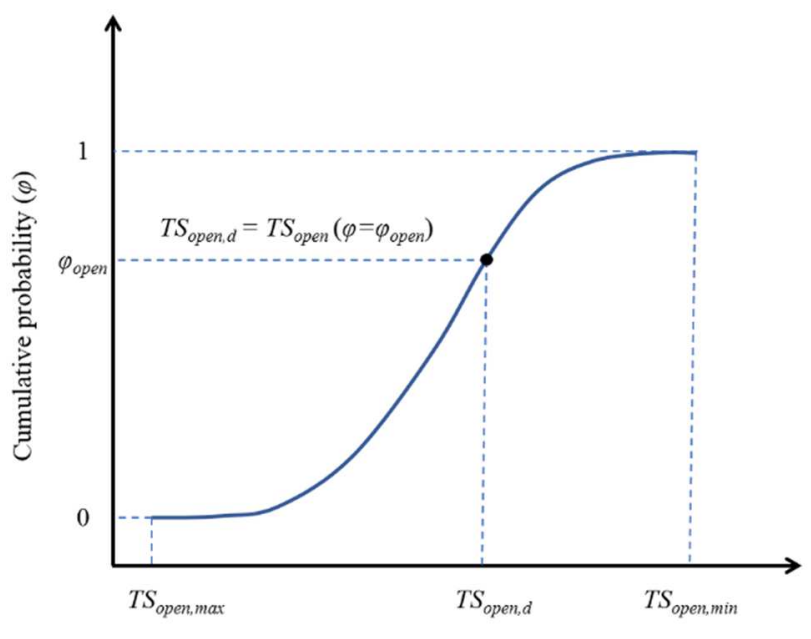

Total solar irradiation during the open period $\left(T S_{\text {open }}\right)$

Fig. 2. The relationship between the total solar irradiation during the open period and cumulative probability.

The fourth step is to use the $E_{p c m}$ to size the PCM storage tank.

$$
E_{p c m}=\left(c_{p c m} m_{p c m}+c_{w} m_{w}\right)\left(T_{h p, m}-T_{s p, d}\right)+
$$

where $c_{p c m}$ and $m_{p c m}$ are the specific heat and mass of the PCM inside the tank; $c_{w}$ and $m_{w}$ are the specific heat 
and mass of the water inside the tank; $T_{h p, m}$ is the maximum temperature that the air-source heat pump can reach up to; $T_{s p, d}$ is the design temperature of the swimming pool; and $H_{p c m}$ is the enthalpy of the PCM.

The last step is to size the air-source heat pump. The heating capacity of the air-source heat pumps is calculated for achieving two goals. One is to make sure that the PCM storage tank can be heated up to the set temperature point (e.g. $60^{\circ} \mathrm{C}$ ) during the charging mode. Another is to ensure that the open-air swimming pool can be heated up to the set point during the preheating mode. The larger one is selected to size the capacity of the air-source heat pumps.

\section{System design optimizations}

Since the percentage contribution $\gamma$ from the solar heat collector and the PCM storage tank will affect the energy performance, thermal comfort and financial performance of the heating system, this section presents a method to investigate the importance of the percentage contribution $\gamma$ regarding these performance indicators. First, a simulation platform for a swimming pool and its lowcarbon heating systems is constructed. Then, using the simulation platform, the energy use of the heating system and the swimming pool water temperature will be generated corresponding to different percentage contribution $\gamma$. Then, these data will be used for comparison analysis and identifying a suitable $\gamma$ to balance these performance indicators.

\subsection{Simulation platform}

The simulated system has a configuration shown in Figure 3. Besides the main components, the system has heat exchangers, pumps, valves, and water pipes.

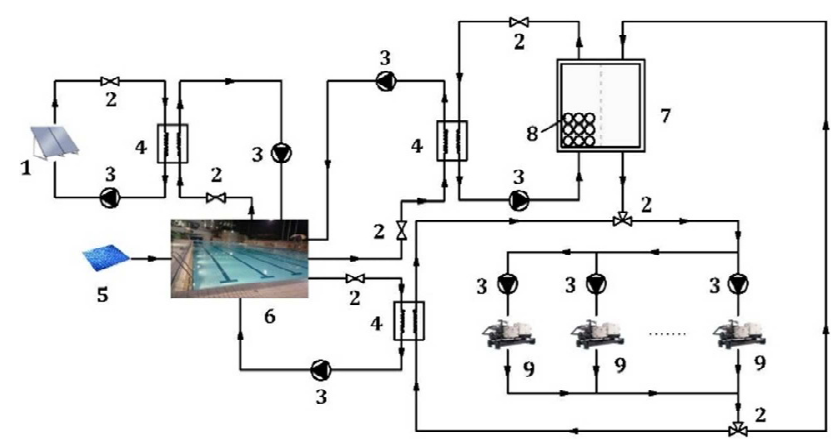

Fig. 3. Configuration of the proposed low-carbon heating system for outdoor swimming pools (1. solar collector; 2 . valve; 3 . pump; 4. heat exchanger; 5 . thermal-insulation cover; 6. open-air swimming pool; 7. PCM storage tank; 8. PCM tube; 9. air-source heat pump)

The simulation of the system was constructed using the professional software of TRNSYS and Matlab. TYPE 71 was used to simulate the solar collectors. The PID controller was realized using TYPE 23. The mixing and diverting valves are simulated by TYPE 649 and TYPE 647, respectively. The thermodynamic models of the
PCM storage tank and the open-air swimming pool were simulated using the model presented in [25]. Both of them were realized using programs. The interface, TYPE 155, was adopted to link the models in TRNSYS and programmes in Matlab.

\subsection{Performance indicators}

The thermal comfort unmet percentage is selected as the technical performance indicator in this study. It is the percentage of the thermal comfort unmet time in the total open time during the open period.

The initial cost and operational cost are selected as the economic performance indicators in this study. The initial investment includes the initial cost of the solar collector, air-source heat pumps, PCM storage tank, heat exchangers, and controllers, etc. The operational cost is made up of on-peak cost and off-peak cost.

The total energy use is selected as the energy performance indicator. The total energy use is made up of the energy use of the pumps and the energy use of the air-source heat pumps.

\subsection{Overall performance evaluation score}

The overall performance evaluation score $\left(S_{o}\right)$ is calculated by the following equations:

$$
S_{o}=x_{t} S_{t}+x_{i} S_{i}+x_{c} S_{c}+x_{e} S_{e}
$$

where $S_{t}, S_{i}, S_{c}$, and $S_{e}$ is the evaluation score of the thermal comfort unmet percentage, initial cost, operational cost, and energy consumption, respectively. $x_{t}, x_{i}, x_{c}$, and $x_{e}$ is the weight factor for the evaluation score of the thermal comfort unmet percentage, initial cost, operational cost, and energy use in the overall performance score, respectively. They should satisfy the following:

$$
x_{t}+x_{i}+x_{c}+x_{e}=1
$$

The $S_{t}, S_{i}, S_{c}$, and $S_{e}$ is calculated by the following equations:

$$
\begin{aligned}
S_{t} & =\frac{t u-t u_{l}}{t u_{m}-t u_{l}} \cdot 100 \\
S_{i} & =\frac{i c-i c_{l}}{i c_{m}-i c_{l}} \cdot 100 \\
S_{c} & =\frac{o c-o c_{l}}{o c_{m}-o c_{l}} \cdot 100 \\
S_{e} & =\frac{e c-e c_{l}}{e c_{m}-e c_{l}} \cdot 100
\end{aligned}
$$

where $t u$ is the thermal comfort unmet percentage; $i c$ is the initial cost; $o c$ is the operational cost; and $e c$ is the total energy use. $l$ and $m$ represents the least and most preferred performance, respectively.

\section{Case studies}

In order to evaluate the performance of the proposed open-air swimming pool heating system, the proposed heating system was applied to a typical outdoor swimming pool of Hong Kong, which has a surface area of $1100 \mathrm{~m}^{2}$. Two weekly analysis for assessing the performance of the system are conducted from $1^{\text {st }}$ 
December 2012 to $7^{\text {th }}$ December 2012, and from $8^{\text {th }}$ December 2012 to $14^{\text {th }}$ December 2012, respectively. The technical performance, economic performance, and energy performance were compared and analysed in three cases.

\subsection{Three cases}

Fig. 4 shows the ten-years statistic results of the total solar irradiation during the open period with the cumulative probability. In this study, the design cumulative probability is 0.5 , and the corresponding total solar irradiation during the open period is $6.77 \mathrm{MJ} / \mathrm{m}^{2}$. Table 1 shows the sizing results of the main components in three typical cases. The solar energy percentage in Case 1, Case 2 and Case 3 are $0 \%, 10 \%$, and $20 \%$, respectively. The area of solar collector, heating capacity of air-source heat pumps, volume of PCM storage tank in Case 1 are $0 \mathrm{~m}^{2}$, $601.7 \mathrm{~kW}$, and $135.8 \mathrm{~m}^{3}$, respectively. The area of solar collector, heating capacity of air-source heat pumps, volume of PCM storage tank in Case 2 are $959.8 \mathrm{~m}^{2}$, $541.5 \mathrm{~kW}$, and $122.2 \mathrm{~m}^{3}$, respectively. The area of solar collector, heating capacity of air-source heat pumps, volume of PCM storage tank in Case 3 are $1919.6 \mathrm{~m}^{2}$, $481.3 \mathrm{~kW}$, and $108.6 \mathrm{~m}^{3}$, respectively.

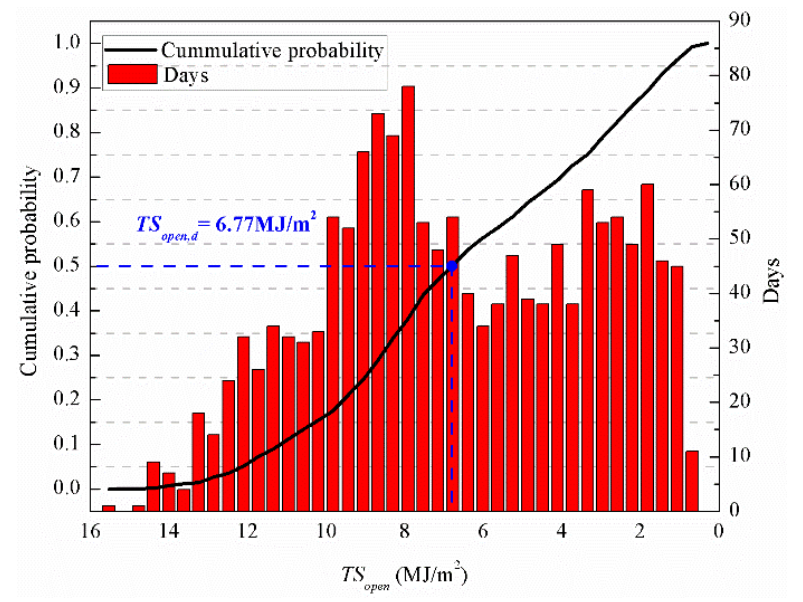

Fig. 4. The variation of the total solar irradiation during the open period with the cumulative probability.

Table 1. Sizing results in three typical cases.

\begin{tabular}{|c|c|c|c|}
\hline Items & Case 1 & Case 2 & Case 3 \\
\hline $\begin{array}{c}\text { Solar energy } \\
\text { percentage }\end{array}$ & $0 \%$ & $10 \%$ & $20 \%$ \\
\hline Area of solar collector & $0 \mathrm{~m}^{2}$ & $959.8 \mathrm{~m}^{2}$ & $1919.6 \mathrm{~m}^{2}$ \\
\hline $\begin{array}{c}\text { Heating capacity of } \\
\text { air-source heat pumps }\end{array}$ & $601.7 \mathrm{~kW}$ & $541.5 \mathrm{~kW}$ & $481.3 \mathrm{~kW}$ \\
\hline $\begin{array}{c}\text { Volume of PCM } \\
\text { storage tank }\end{array}$ & $135.8 \mathrm{~m}^{3}$ & $122.2 \mathrm{~m}^{3}$ & $108.6 \mathrm{~m}^{3}$ \\
\hline
\end{tabular}

\subsection{Technical performance comparison}

In Week 1, the thermal comfort unmet percentage in all the cases are $0 \%$; and in Week 2, the thermal comfort unmet percentage in all the cases are $0 \%$. The average thermal comfort unmet percentage in all the cases are $0 \%$. Hence, the thermal comfort unmet percentage in Case 1 is the same with that in Case 2 and Case 3, which suggests that the technical performance in Case 1 is the same with that in Case 2 and Case 3. In addition, the water temperature of the pool can be well maintained within the thermal comfort range in all cases. The corresponding evaluation score of the thermal comfort unmet percentage is 1,1 and 1 , respectively.

\subsection{Economic performance comparison}

Fig. 5 shows the operational cost comparison between three cases and the corresponding evaluation score comparison between three cases. In Week 1, the operational cost in Case 1, Case 2 and Case 3 are 19931 HKD, 18269HKD and 16682HKD, respectively. In Week 2 , the operational cost in Case 1, Case 2 and Case 3 is 20176HKD, 18348HKD, and 16455HKD respectively. The average operational cost in Case 1, Case 2 and Case 3 is 20054HKD, 18309HKD and 16569HKD, respectively. Hence, the operational cost in Case 2 is $8.7 \%$ less than that in Case 1, and the operational cost in Case 3 is $17.4 \%$ less than that in Case 1 . The corresponding evaluation score of the operational cost is $0,0.5$ and 1 , respectively.
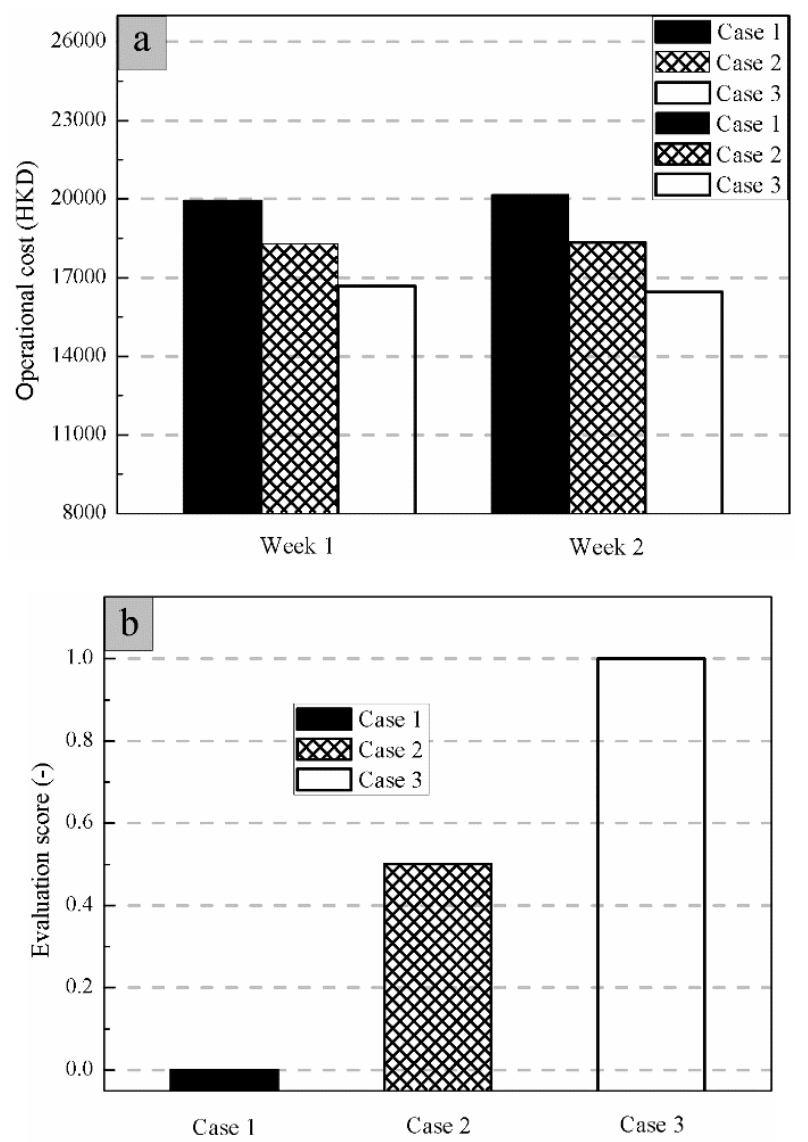

Fig. 5. (a) Operational cost and (b) corresponding evaluation score comparison between three cases. 
Fig. 6 shows the initial cost comparison between three cases and the corresponding evaluation score comparison between three cases. The initial investment in Case 1, Case 2 and Case 3 are 2739kHKD, 3261kHKDand $3767 \mathrm{kHKD}$, respectively. Hence, the initial investment in Case 1 is $16.0 \%$ less than that in Case 2 and $27.3 \%$ less than that in Case 3. The corresponding evaluation score of the initial cost in Case 1, Case 2 and Case 3 are 1, 0.49, and 0 , respectively.
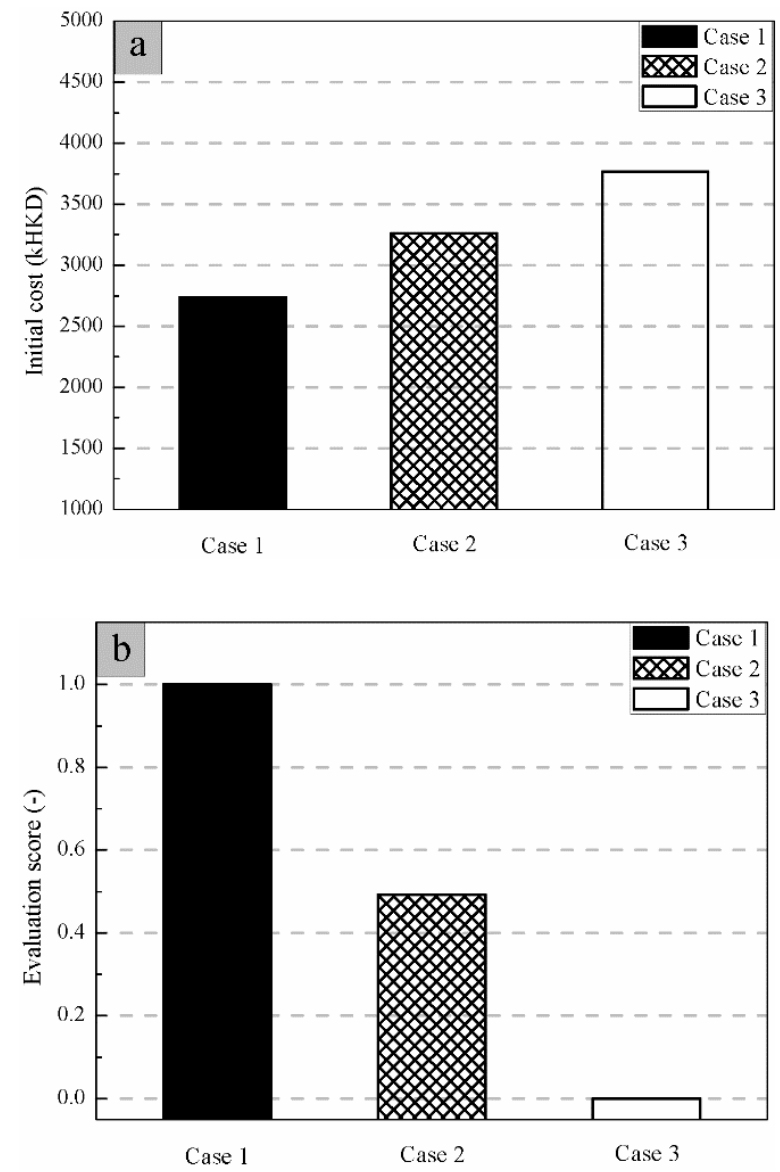

Fig. 6. (a) Initial investment cost and (b) corresponding evaluation score comparison between three cases.

\subsection{Energy performance comparison}

Fig. 7 shows the total energy use comparison between three cases and the corresponding evaluation score comparison between three cases. In Week 1, the total energy use in Case 1, Case 2 and Case 3 are 86.3GJ, 78.9GJ and 71.8GJ, respectively. In Week 2, the total energy use in Case 1, Case 2 and Case 3 are 87.6GJ, 79.3GJ and 70.6GJ, respectively. The average total energy use in Case 1, Case 2 and Case 3 are 87.0GJ, $79.1 \mathrm{GJ}$ and $71.2 \mathrm{GJ}$, respectively. Hence, the total energy use in Case 2 is $9.1 \%$ less than that in Case 1, and the total energy use in Case 3 is $18.2 \%$ less than that in Case 1 . The corresponding evaluation score of the total energy use in Case 1, Case 2 and Case 3 are 0, 0.5, and 1, respectively.
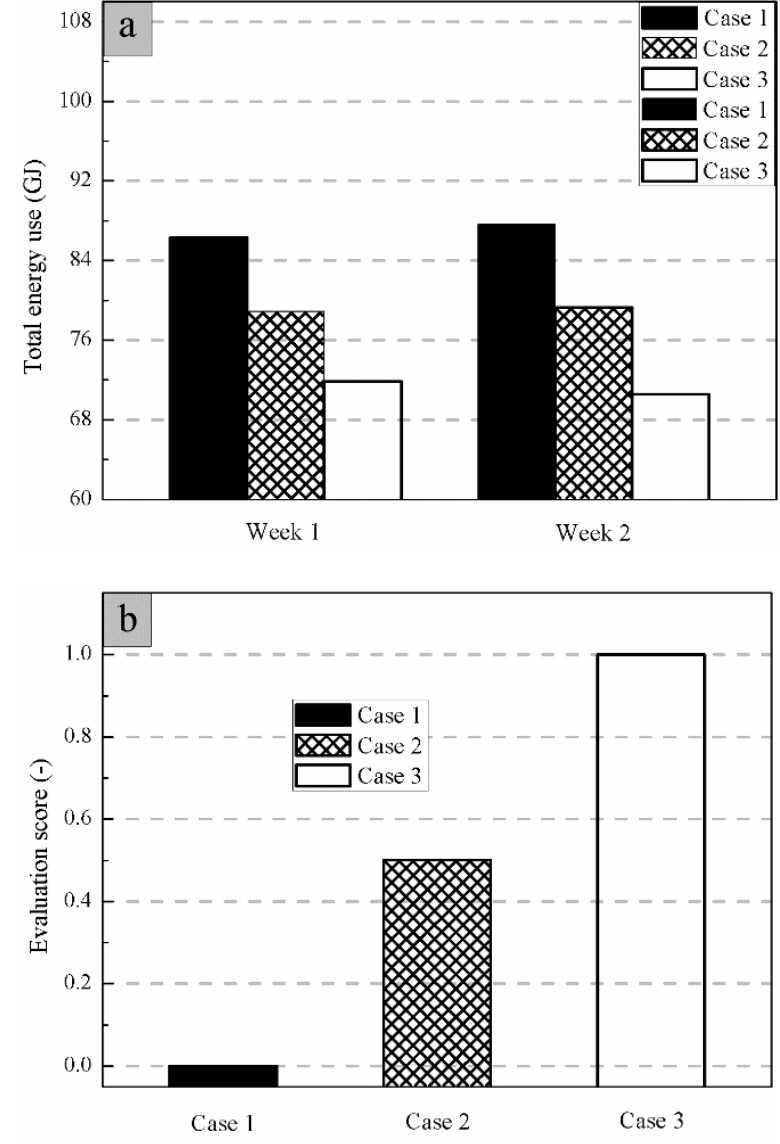

Fig. 7. (a) Total energy use and (b) corresponding evaluation score comparison between three cases.

\subsection{Overall performance comparison}

Fig. 8 shows the overall performance comparison between three cases. In this study, the weight factor for the evaluation score of the thermal comfort unmet percentage, initial cost, operational cost, and energy use in the overall performance score is $0.25,0.25,0.25$, and 0.25 , respectively. The overall performance evaluation score in Case 1, Case 2 and Case 3 is 0.50, 0.62, and 0.75, respectively. Hence, the optimal case is Case 3 in which the solar energy percentage is $20 \%$.

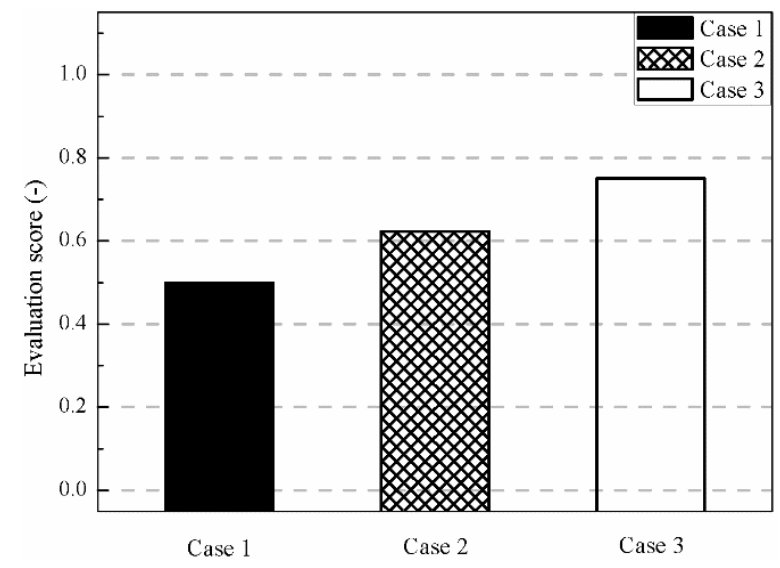

Fig. 8. Overall performance comparison between three cases. 


\section{Conclusions}

The proposed low-carbon heating system for outdoor swimming pools uses air-source heat pumps and solar heat collectors collects heat from ambient air and solar radiation, respectively. The working principle and sizing approach of the system are introduced in detail. The heating system has been evaluated in a simulation environment regarding thermal comfort unmet percentage, initial cost, operational cost, and total energy use. Results indicate that the water temperature of the open-air swimming pool in all cases can be maintained within the thermal comfortable range. The weekly operational cost can be saved by $17.4 \%$ when the solar energy percentage increases from $0 \%$ to $20 \%$. The initial cost will be increased by $27.3 \%$ when the solar energy percentage increases from $0 \%$ to $20 \%$. The weekly total energy use can be saved by $18.2 \%$ when the solar energy percentage increases from $0 \%$ to $20 \%$. The overall performance evaluation score in Case 1, Case 2 and Case 3 is 0.50, 0.62, and 0.75 , respectively. Hence, the optimal case is Case 3 in which the solar energy percentage is $20 \%$.

\section{Acknowledgements}

The work described in this paper was supported by the fund of CityU SRG (No. 7004873).

\section{References}

1. TT. Chow, Y. Bai, KF. Fong, Z. Lin, Appl. Energy 100, 309-17 (2012)

2. JLF. Blazquez, IR. Maestre, FJG. Gallero, PA. Gomez, Build. Environ. 138, 293-9 (2018)

3. ME. Kuyumcu, H. Tutumlu, R. Yumrutas, Energy Convers. Manag. 121, 349-57 (2016)

4. LA. Tagliafico, F. Scarpa, G. Tagliafico, F. Valsuani, Energy Build. 55, 833-40 (2012)

5. A. Mousia, A. Dimoudi, Energy Build. 90, 166-72 (2015)

6. W. Lee, K. Kung, Appl. Therm. Eng. 28, 1647-53 (2008)

7. DA. Katsaprakakis, Energy 81, 738-53 (2015).

8. Y. Yadav, G. Tiwari, Energy Convers. Manag. 27, 49-54 (1987)

9. C. Rakopoulos, E. Vazeos, Energy Convers. Manag. 27, 189-95 (1987)

10. B. Molineaux, B. Lachal, O. Guisan, Sol. Energy 53, 21-6 (1994)

11. W. Haaf, U. Luboschik, B. Tesche, Sol. Energy 53, 41-6 (1994)

12. R. Croy, FA. Peuser, Sol. Energy 53, 47-52 (1994)

13. A. Dang, Energy Convers. Manag. 26, 27-31 (1986)

14. GP. Greyvenstein, JP. Meyer, Energy 16, 1031-7 (1987)

15. JC. Lam, WW. Chan, Energy Convers. Manag. 42, 1299-306 (2001)
16. JC. Lam, WW. Chan, Energy Convers. Manag. 44, 1625-31 (2003)

17. WW. Chan, JC. Lam, J. Sustain. Tourism 11, 74-83 (2003)

18. A. Somwanshi, AK. Tiwari, MS. Sodha, Energy Convers. Manag. 68, 89-95 (2013)

19. D. Borge, A. Colmenar, M. Castro, S. Martín, E. Sancristobal, Energy Build. 43, 3161-72 (2011)

20. C. Harrington, M. Modera, Energy Build. 59, 252-64 (2013)

21. G. Zsembinszki, MM. Farid, LF. Cabeza, Sol. Energy 86, 567-77 (2012)

22. Z. Tian, B. Perers, S. Furbo, J. Fan, Energy 142, 1308 (142)

23. B. Ahlgren, Z. Tian, B. Perers, J. Dragsted, E. Johansson, K. Lundberg, Energy Convers. Manag. 174, 295-308 (2018)

24. Y. Li, G. Huang, T. Xu, X. Liu, H. Wu, Appl. Energy 209, 224-35 (2018)

25. Y. Li, G. Huang, H. Wu, T. Xu, Appl. Therm. Eng. 134, 490-500 (2018) 